\title{
Construction of "T" Talents Training Mode for Cross-Border E-commerce Industry
}

\author{
Mingxia Zhong \\ Zhejiang Vocational College of Commerce, Hangzhou 310053, China \\ 517997106@qq.com
}

\begin{abstract}
Since the establishment of Hangzhou cross border e-commerce comprehensive pilot zone in 2015, the cross-border e-commerce industry in Hangzhou has developed rapidly. This year, the Hangzhou municipal government proposed the need of "building the digital silk road strategy", which will give birth to the huge demand for professional talents in the cross-border e-commerce industry in Hangzhou, and make the cultivation of innovative application-oriented talents to meet the needs of the industry become an important problem to be solved. The purpose of this project is to explore an application-oriented innovative talent training mode to meet the needs of regional economic development, and put forward a talent training mode of "two libraries and four platforms", so as to effectively realize the seamless connection among universities, enterprises and governments and the cultivation of innovative talents.
\end{abstract}

Keywords: Cross border e-commerce; digital economy; T-type talents; two libraries and four platforms.

\section{面向行业需求的跨境电商“T”型人才培养模式构建}

\author{
钟明霞 \\ 浙江商业职业技术学院，杭州，中国
}

摘 要：自2015年杭州跨境电商综合试验区成立以来杭州跨境电商产业得到迅速发展，今年 杭州市政府又提出了 “打造数字丝绸之路战略” 的需要, 将催生杭州对跨境电商行业专业化 人才的巨大需求，使得面向行业需求的创新型应用型人才培养成为亟待解决的重要问题。本 项目旨在探索一种适应区域经济发展需要的应用型创新型人才培养模式，提出了 “两库四平 台” 的人才培养模式, 以有效实现高校、企业、政府三者之间的无缝对接和创新人才的培养。

关键词：跨境电商；数字经济； T型人才; 两库四平台.

\section{1. 引言}

杭州作为全国首批建立的跨境电商综试区城市，从2015年3月经国务院批准设立到现在已经 “四岁”，经过这四年的努力和创新，杭州的跨境电商上线企业数量和交易额都有了显著的 增长，2018年杭州跨境电商上线企业数量达到了12000多家，跨境电商交易额达到113.7亿美 元，比2014年增长了近600倍 [1]。

今年3月29日，杭州市副市长胡伟在 “数” 说跨境2019中国（杭州）跨境电商综合试验区创新 发展大会上解读了作为杭州综试区未来 3 年的行动纲领 - 《打造数字丝绸之路战略枢纽实施方 案》 [2], 发挥杭州以跨境电商为代表的数字贸易优势, 积极拓展以 '一带一路' 沿线国家和 地区为代表的新兴市场, 发挥杭州作为全国首个跨境电商综试区的引领带动作用, 依托数字 贸易线上线下平台，加快实现信息流、人才流、资金流、货物流、服务流等经济要素的集聚， 进而促进城市经济能级和发展地位的跃升。

基于如上所述杭州跨境电商产业的迅速发展与打造数字丝绸之路战略的需要, 将催生杭州对 跨境电商行业专业化人才的巨大需求，使得面向行业需求的创新型应用型人才培养成为亟待 解决的重要问题。在当下 “一带一路” 的背景下，浙江高校需要充分借助杭州 “打造数字丝 
绸之路战略” 的相关倡议和实施细则, 不断强化人才培养模式, 提升服务区域经济的意识和 能力, 使人才培养目标与区域经济的人才需求相适应。而探索一种高效、优质、创新的适应 区域经济发展的应用型人才培养模式，是摆在高校面前的一项重要任务。

\section{2. 研究的内容}

本文旨在探索一种适应区域经济发展需要的应用型创新型人才培养模式, 提出了 “两库四平 台” 的人才培养模式, 以有效实现高校、企业、政府三者之间的无缝对接和创新人才的培养。 本文研究内容围绕 “打造数字丝绸之路战略” 下跨境电商企业人才需求、“两库四平台” 跨 境电商人才培养模式、跨境电商 “ $\mathrm{T}$ ” 型人才培养创新等重点领域展开产教深度探讨, 打造特 色教育生态链, 赋能教育创新。

\section{1. 跨境电商企业人才需求}

就当前杭州跨境电商发展过程中存在明显跨境电商人才缺失的问题和人才跨境电商职业能力 不足的问题，本课题组成员经过前期的全面调研和分析后，发现 “打造数字丝绸之路战略” 背景下跨境电商企业对人才的需求重点表现在复合型应用人才的需求。

因为跨境电商是典型性的复合性学科, 体现在经济学、管理学、信息技术、外语等学科的交 叉和整合。企业对跨境电商复合型人才的能力要求, 既有较深的专业知识, 又有广博的知识 面, 这种人才结构不仅在横向上具备比较广泛的一般性知识修养, 而且在纵向的专业知识上 具有较深的理解能力和独到见解, 较强的创新能力, 如下图1所示。

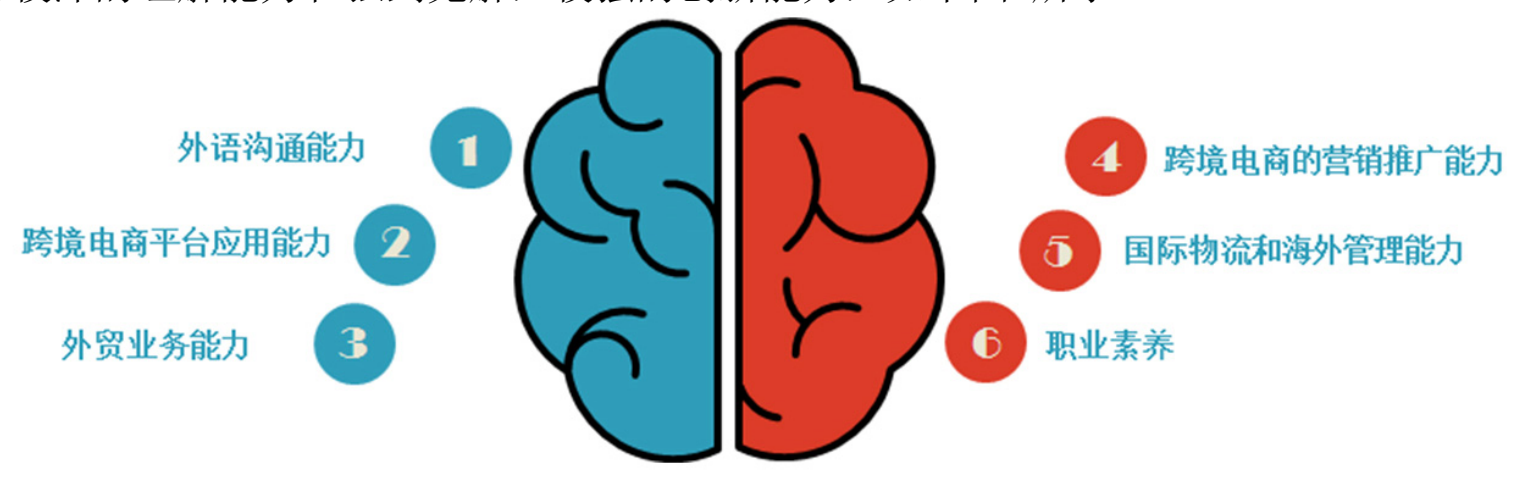

图1. 跨境电商复合型人才能力要求

根据前期企业调查显示, 企业实际缺的不是纯技术性或是高级管理人才, 缺少却是真正能够 具备综合能力的跨境电商复合型人才, 这类人才的职业优势是实践经验强, 易于切入岗位; 就业能力高, 易于加入企业; 职业素养高, 易于融入社会。

\section{2. “两库四平台” 跨境电商人才培养模式}

本课题重在研究 “两库四平台” 跨境电商高职人才培养模式的构建, 两库是指建设专业的数 字教学资源库和创新创业资源库, 四平台是指智慧学习平台、实践教学平台、跨境电商操作 交易平台和联盟平台, 如下图2所示, 期望通过该人才培养模式的构建做到专业设置与企业需 求相协调、技能训练与岗位要求相协调、培养目标与用人标准相协调, 以求培养出为跨境电 商企业量身定做的人才。 


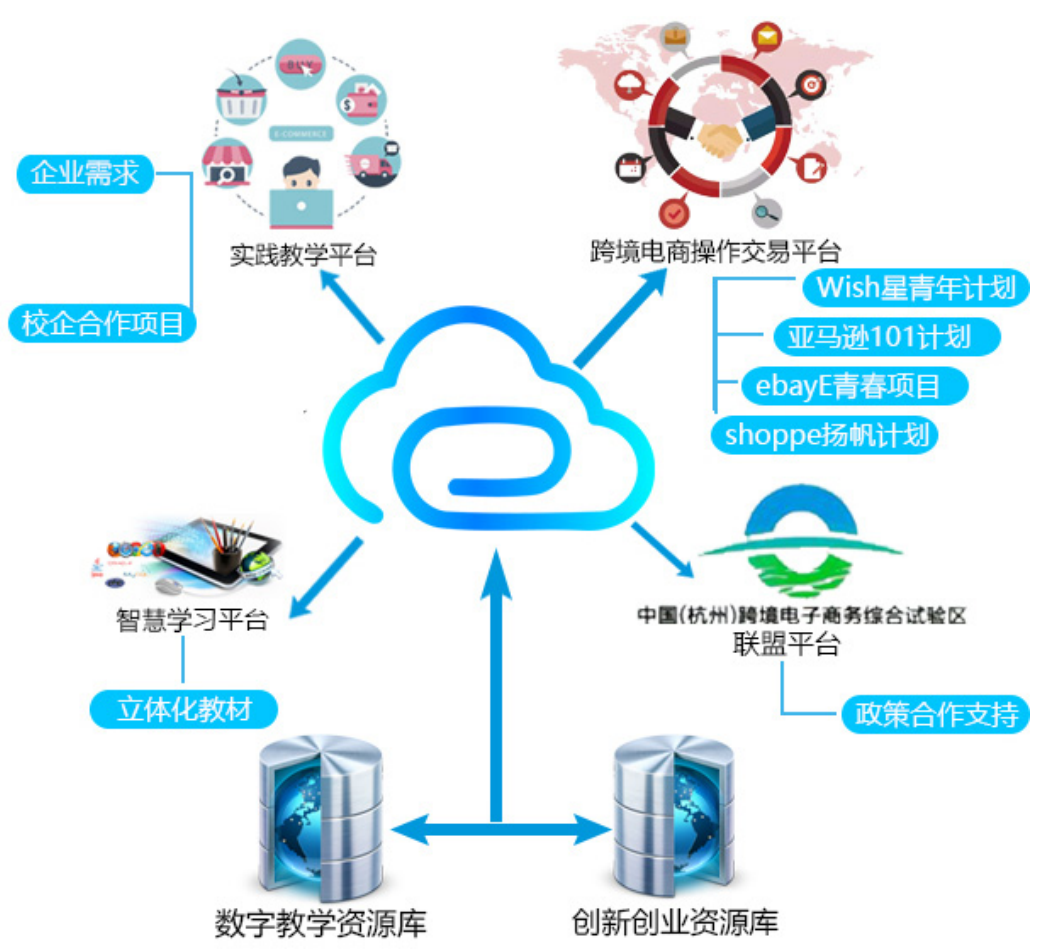

图2. “两库四平台”跨境电商人才培养模式

\section{2 .1 数字化教学资源库}

搭建数字化教学资源库主要包括两项内容的工作：第一，在跨境电商企业与高校之间建立联 合培养机制，完成跨境电商课程群及线上课程建设等工作，专业所有课程有效数字化，并纳 入资源库，供高校、校外企业等机构共享。第二，立体化教材的建设工作，立体化教材需要 联合高校教师和阿里巴巴、Amazon、Wish、eBay 等各大跨境电商平台，按照跨境电商岗位职 业能力发展过程编写。所谓的立体化教材，是搭配视频、音频、网络的 “立体书”，除了书， 还附带了 PPT 课件、慕课视频、实训案例、音频资源以及作业、试卷、主题讨论等电子学习 资源。

\section{2.2 创新创业资源库}

将高校师生的创新创业理念放入资源库，供企业选择；企业的创新技术难点可以随时输入到 资源库中，供高校进行技术研究。同时依托联盟平台组织举办跨境电商可持续发展论坛、跨 境电商实验班、研修班等活动，启动省级跨境电商虚拟仿真实验空间建设、联盟成员高校间 的教师兼聘制度建设等创新工作。

\section{2.3 联盟平台}

联盟平台的建立有助于形成真正的产学研联盟, 及时沟通交流, 实现区域内机构、高校、企 业之间的共享与合作，发展区域经济。

比如在杭州, 中国（杭州）跨境电商人才联盟即由浙江13所涉跨境电商相关高校，10家跨境 电商平台、企业、中介机构联合发起成立, 并以浙江省教育厅与杭州跨境电商综试办为联盟 指导单位, 旨在创建具有中国 (杭州) 跨境电商综试区特色的人才服务与资源平台, 提升跨 境电商人才的培养质量，开展多层次跨境电商人才培训，提高跨境电商研究水平。

联盟会提供对应的杭州综试区政策支持, 同时在今年还筹建跨境电商人才捊化基地, 推动联 盟成员高校有志于跨境电商的大学生进行创业，联盟对接企业提供场地与政策方面的便利。 有联盟平台的支持将加快跨境电商专业人才的培养和输出, 助力杭州甚至全国的跨境电商人 才培养体系的改革。 


\section{2 .4 实践教学平台}

跨境电商专业需要进行大量的实训教学, 实训课程不能仅依靠校内实训室, 需要很多跨境电 商平台例如速卖通和亚马逊需要有相关企业委托才能设立店铺, 所以实训教学的开展应依靠 稳固的校企合作关系, 同时在校外设立企业实训基地, 按照真实的工作场景和工作岗位需求 进行实训教学, 提升实训教学质量。

校企合作采用两条交叉的主线同时进行，一条线在校内人才的考察培养可以按照跨境电商具 体岗位的生命周期来设定, 当前一阶段的学习结束之后, 还能够根据个人或企业的岗位需求, 进入到更高层次专门人才培养的下一循环之中。同时采用 “课程实践+顶岗实习+企业实战+毕 业实习” 多层次分步递进构建完善的实践体系。另一条线要企业通过与高校合作, 成立校外 实训基地, 充分开展真实企业项目, 持续推动高校的课程内容与教学方式的改革, 以产学研 协同的方式培育产业亟需的各类人才。这样学生可以凭借在学校里学到的最新知识和技能, 迅速投入到工作当中。

两条交叉的主线, 精确匹配了人才供给双方的需求。一方面为学院的毕业生提供就业指导, 另一方面也为杭州的跨境电商产业, 输送大批优秀的专业人才。

\subsection{5 智慧学习平台}

智慧学习平台是一个基于 “质量监控平台”（含评估平台）的数据分析学习平台，用于监控 学生对技术的掌握和跟踪其评估 [3]。在此基础上, 分析学生在知识掌握方面的优缺点。智慧 学习平台提供了教学内容的片段和提前学习的补充。根据学生在知识点或技术点上的优缺点, 制定有针对性的学习内容。而且, 那些在学习评价中获得高分的学生也可以找到自主学习的 内容向前推进, 实现个性化的学生服务。

同时, 高校还可以联合中国 (杭州) 跨境电商人才联盟推动跨境电商 “微专业”、“微学位”、 “微课程”的建设工作和学分互选、互认工作。

\section{2 .6 跨境电商操作交易平台}

培养跨境电商复合型人才必须以未来就业岗位的实际技能为导向, 一方面高校需要和各大跨 境电商平台 eBay、速卖通、Amazon 、Wish、Shopee 等平台合作进行丰富的产学研合作, 将 通过把 “企业搬进校园” 培养学生动手能力, 在实践育人培养过程中实现人才培养的创新, 比如建立跨境电子商务创业工作室, 学生按自己的兴趣加入相应的工作室, 工作室与相应的 企业合作, 承担项目, 以真实平台、真实产品、真实外贸流程, 培养学生创业创新意识。另 一方面, 由中国 (杭州) 跨境电商人才联盟组织 “新生力量” 培养计划, 联合各大跨境电商 平台在各大高校培育行业新生力量, 比如组织Wish “星青年” 计划、亚马逊101计划, 提供学 生使用沙盒软件模拟真实账号运营的方式快速覆盖全国各地高校, 帮助高校学生了解跨境电 商贸易, 助力中国大学生创业就业。同时, eBay E 青春项目、Shoppe 扬帆计划等将陆续推出, 目标直指跨境电商 “新生力量”。

\section{3. 跨境电商 “ $\mathrm{T}$ ” 型人才培养创新}

随着数字经济时代的到来, 企业对跨境电商复合型人才的能力要求其实是学生应成为 “ $\mathrm{T}$ ” 型 人才, $\mathrm{T}$ 型人才是指按知识结构区分出来的一种新型人才类型。用字母 “ $\mathrm{T}$ ” 来表示他们的知 识结构特点。“-”表示有广博的知识面, 要求学生通览各方面的知识。“|”表示知识的深 度, 代表专业基础知识必须扎实, 学生不但要掌握必要的书本知识, 还要在实践中培养自身 解决问题的实际能力。

\subsection{1 跨境电商 “ $\mathrm{T}$ ” 型人才培养理念}

跨境电商 “ $\mathrm{T}$ 型人才” 是拥有 “宽泛扎实的理论基础+专业深入的技术技能+精准涃熟的实践 经验” 的人才。这种人才无论在理论知识架构、岗位工作技能, 还是项目的实践操作上, 都 会成为企业的 “多面手”。 


\subsection{2 跨境电商 “ $\mathrm{T}$ ” 型人才培养方式}

以就业为导向, 以实践为特色, 直接面向企业应用。实践训练上, 利用校内外实训体系 + 创新 创业工作室+联盟平台, 引用真实的跨境电商平台项目案例, 模拟企业工作环境, 让学员在项 目进程中扮演不同角色, 遭遇各种问题, 使学员没有进入企业之前, 就熟悉企业的工作环境, 熟悉工作的流程，这样就做到了真正的以就业为导向、以实践为特色。

\subsection{3 跨境电商 “ $\mathrm{T}$ ” 型人才培养目标}

目标是培养能够满足跨境电商企业要求的复合型人才，如下图3所示。

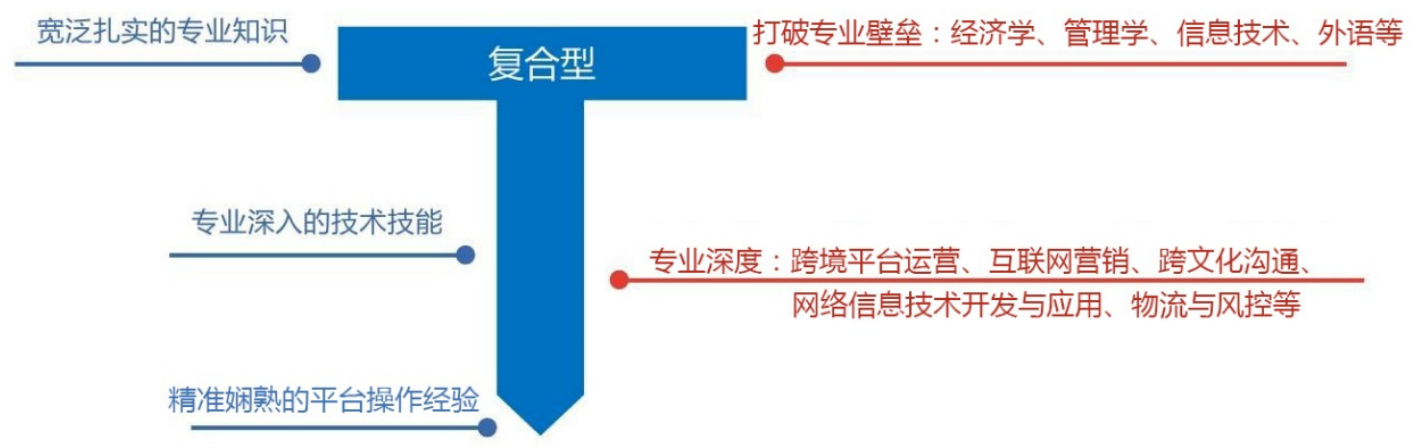

图3. 跨境电商 “ $\mathrm{T}$ ” 型人才

\section{3. 总结}

本课题研究对于高职院校跨境电商人才培养模式的改革和数字经济时代其他领域创新创业应 用型人才的培养也有很好的借鉴意义。

(1) 改变现有的人才培养模式, 结合当下跨境电商行业发展现状, 明确人才培养的目的和未来 方向，构建系统化的跨境电商人才培养体系，规范师资队伍建设，深化校企合作。

(2) 当下是数字经济时代, 两库四平台正是以数字化的知识和信息为关键生产要素, 以数字技 术创新为核心驱动力, 通过数字技术与实体经济深度融合, 实现人才和跨境电商产业的数字 化转型, 同时促进整体行业的发展, 从而创造出更多的工作岗位, 促进就业。

\section{References}

[1]. Information on: http://www.china-hzgec.gov.cn/.

[2]. Information on: http://tradeinservices.mofcom.gov.cn/article/news/gnxw/201904/80595.html.

[3]. Huan-Song Yang, Jia-Ping Wu. Exploration on Cultivation of Application-Oriented and Innovative Talents in the Information Field under "Internet +" Environment. EURASIA Journal of Mathematics Science and Technology Education. Vol. 13(2017) No.8, p.5607-5614. 